\title{
A novel spinal brace in management of scoliosis due to cerebral palsy. Radiological and subjective clinical results after at least one year of treatment
}

\author{
Ichiro Kajiura*, Yu Moriguchi, Yoshihiro Matsui, Tokimitsu Morimoto, Yohei Matsuo, Motoki Iwasaki, \\ Tsunehiko Suzuki \\ From 10th International Conference on Conservative Management of Spinal Deformities - SOSORT 2013 \\ Annual Meeting \\ Chicago, IL, USA. 8-11 May 2013
}

\section{Background}

Severe scoliosis in patients with cerebral palsy (CP) causes difficulty in sitting balance and creates increased nursing demands. Surgical stabilization has proven to be a valuable method to stop the progression of scoliosis [1]. However, the complication rate after such surgery is substantial[2]. Additionally, many patients with quadriplegia and large curvatures of the spine have impaired general health, epilepsy and reduced respiratory capacity, making them poor candidates for major surgery like spine fusion. Therefore, other treatment alternatives should be available. We have recently developed a spinal brace named Dynamic Spinal Brace (DSB), which is a custom-molded, polycarbonate orthosis characterized by lightness and flexibility. Unlike the other underarm orthoses, DSB does not fix the pelvic girdle rigidly and, thus, potentially contributes to good compliance with bracing.

\section{Purpose}

The purpose of this study was to examine the efficacy of DSB for the management of scoliosis in $\mathrm{CP}$ patients.

\section{Methods}

A total of 151 patients with $\mathrm{CP}$ and scoliosis have been treated by DSB (age: $14.3 \pm 8.2$ years). The mean follow-up period was $33.9 \pm 11.9$ months. Periodic $x$-ray tests in the sitting position were performed in order to evaluate in-brace correction and curve progression.

\footnotetext{
* Correspondence: u_in_music@wj8.so-net.ne.jp

Osaka Developmental Rehabilitation Center Minami Osaka Hospital for Handicapped Children, Osaka, Japan
}

\section{Conclusions and discussion}

Many of the spinal braces designed for idiopathic scoliosis do not necessarily match the needs of CP patients with more complicated medical conditions. DSB is specifically designed for CP patients and, therefore, showed good compliance, moderate in-brace correction equivalent to precedent braces[3], and potential contributions to improvement of the ADL of the patients. Although the preventive impact on curve progression remains to be elucidated by the longer follow-up, DSB could be an option for the management of scoliosis in $\mathrm{CP}$ patients.

\section{Published: 18 September 2013}

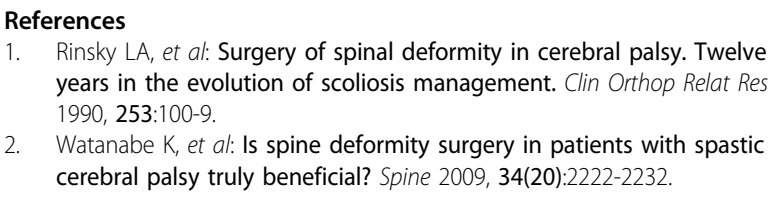
years in the evolution of scoliosis management. Clin Orthop Relat Res 1990, 253:100-9.

2. Watanabe $K$, et al: Is spine deformity surgery in patients with spastic cerebral palsy truly beneficial? Spine 2009, 34(20):2222-2232. 
3. Terjesen T, et al: Treatment of scoliosis with spinal bracing in quadriplegic cerebral palsy. Dev Med Child Neurol 2000, 42(7):448-54

doi:10.1186/1748-7161-8-S2-049

Cite this article as: Kajiura et al: A novel spinal brace in management of scoliosis due to cerebral palsy. Radiological and subjective clinical results after at least one year of treatment. Scoliosis 2013 8(Suppl 2):O49.

Submit your next manuscript to BioMed Central and take full advantage of:

- Convenient online submission

- Thorough peer review

- No space constraints or color figure charges

- Immediate publication on acceptance

- Inclusion in PubMed, CAS, Scopus and Google Scholar

- Research which is freely available for redistribution

Submit your manuscript at www.biomedcentral.com/submit 